Abstract

\title{
New Methodology to Access 1,5-Disubstituted 1,2,3-Triazoles ${ }^{+}$
}

\author{
Virgyl Camberlein *, Ronan Gealageas, Benoit Deprez, Rebecca Deprez and Damien Bosc \\ Inserm - Institut Pasteur de Lille, U1177-Drugs and Molecules for Living Systems, Université de Lille, \\ 59006 Lille, France; ronan.gealageas@univ-lille.fr (R.G.); benoit.deprez@univ-lille.fr (B.D.); \\ rebecca.deprez@univ-lille.fr (R.D.); damien.bosc@univ-lille.fr (D.B.) \\ * Correspondence: virgyl.camberlein@univ-lille.fr \\ † Presented at the 2nd Molecules Medicinal Chemistry Symposium (MMCS): Facing Novel Challenges in \\ Drug Discovery, Barcelona, Spain, 15-17 May 2019.
}

Published: 14 November 2019

\begin{abstract}
: 1,2,3-triazole is a well-known scaffold that is commonly encountered in bioactive compounds, such as antimicrobial, antiviral, and anticonvulsant drugs. The structural properties of 1,2,3-triazole enable it to mimic different chemical functions, such as amides, esters or some heterocycles, justifying its broad use as a bioisostere to synthesize novel bioactive molecules. Moreover, they are remarkably stable to metabolic transformations. In the 2000s, the use of 1,2,3triazole in medicinal chemistry was intensified due to the copper catalyzed azide-alkyne cycloaddition ( $\mathrm{CuAAc}$ ) methodologies reported simultaneously by Sharpless et al. and Meldal et al., affording the regioselective formation of 1,4-disubstituted 1,2,3-triazoles. By contrast, the regioselective formation of the 1,5-disubstituted regioisomer is less described. Krasiński et al. developed a methodology from an azide and a magnesium acetylide. Hlasta et al. described a method from an azide and an alkyne substituted by a trimethylsilyl group. However, these two methodologies are quite difficult to set up. In recent years, catalytic synthetic pathways have appeared using either ruthenium (RuAAC) or nickel (NiAAC) catalysts. However, despite all these efforts, the scope of substrates is quite limited, preventing the formation of fully functionalized molecules of interest. In order to improve the access of 1,5-disubstituted 1,2,3-triazoles, we have developed a new methodology. The conditions screening and the scope and limitations will be presented.
\end{abstract}

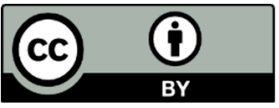

(C) 2019 by the authors. Licensee MDPI, Basel, Switzerland. This article is an open access article distributed under the terms and conditions of the Creative Commons Attribution (CC BY) license (http://creativecommons.org/licenses/by/4.0/). 